\title{
Effects of Work Life Balance on Staff Performance in the Telecommunication Sector in Kenya
}

\author{
Dinah C. Keino \\ Director, Quality Assurance, Management University of Africa \\ Nairobi, Kenya Phd candidate, Jkuat \\ Dr. Peter Paul Kithae \\ Director, Open and Distance Learning \\ Management University of Africa, Nairobi, Kenya
}

\begin{abstract}
Work-life balance practices have positive impact on employee performance in an organisation in as much as work life imbalance has also been proved to have side effects of wellbeing of employees. This study looked at the effect of work life balance on staff performance in the telecommunication sector in Kenya. It used role theory and spill over theory to support the research. Descriptive research design was adopted in order to provide a framework to examine current conditions, trends and status of events regarding work life balance. The target population of the study was $\mathbf{3 9 0}$ senior staff working at Safaricom, Airtel, Telkom Kenya's Orange and Essar Kenya's Yu Headquarters in Nairobi. The study focused on the three levels of management who are directly dealing with the day to day management of the companies. Stratified random sampling technique was used since population of interest is not homogeneous and could be subdivided into groups or strata to obtain a representative sample. Structured questionnaires were used as method of data collection. Data analysis was done using both qualitative and quantitative methods. From the findings, it was evident that work life balance factors such as long working hours, overtime, lack of vacation, family responsibilities and family work conflict all negatively affects staff performance at work. The study recommended among others that companies in the telecommunication sector in Kenya need to review overtime working policy; introduce rotational work; adopt use of delegation and support employees through counseling and resources to meet family expectations and responsibilities. Finally, this study suggests that future studies explore other work life balance factors that could affect staff performance.
\end{abstract}

Key words: work related factors, Family life, work life balance, staff performance, telecommunication sector in Kenya

Institution: The Management University of Africa

\section{INTRODUCTION AND RESEARCH OBJECTIVES}

In today's society, workplace pressures continue to mount globally. Work target demands, family pressure and the pressure to balance the two have taken a toll on most employees' health and well-being (Parus, 2010). Employers, faced with skyrocketing healthcare costs, global competition and economic uncertainty, are concerned about attracting and retaining high-quality employees and delivering superior organizational performance. As a result, some companies such as Apple in United States, Nokia in China and British Bureau of Statistics in 
London among others have responded to this business challenge by taking care of their employees work life issues. These employers then create workplaces that do more than just improve productivity - they do not build a strong, vibrant organizational culture that supports the company itself but a psychologically healthy workplace (Greenhaus \& Beutell, 2010).

In Kenya, the telecommunication industry is highly competitive. It is characterized by aggressive pricing and marketing strategies as well as rapid deployment of new technologies. Cuilenburg and Slaa (2010) indicates that mobile telecommunications operators compete for customers principally on the basis of services offered, pricing, marketing skills, quality, reliability and coverage area. As market saturation approaches, the focus of competition will likely shift from customer acquisition and customer retention to staff attraction and retention.

\section{Statement of the Problem}

Work-life balance is defined as an employee's perception that multiple domains of personal time, family care, and work are maintained and integrated with a minimum of role conflict (Greenhaus \& Beutell, 2010). According to Dex \& Smith (2012), Work life balance (acronym WLB) is the separation between work life and personal life of an employee in the organization. It is the boundary that one creates between the professional life, career advancement, personal life or any other segment that makes up the life of an individual. Apart from the career life, these segments include family, personal growth, fitness and health, community relations and friendship. Finding the balance between career and personal life has always been a challenge for working people.

William (2010) explains that a psychologically healthy workplace fosters employee health and well-being as well as enhancing organizational performance, thereby benefiting both employees and the employer. This is realized in form of increased job satisfaction, higher morale, better physical and mental health, enhanced motivation, and improved ability to manage stress (Raphael, 2011). Ohkubo (2012) adds that well managed work life balance programs could benefit the organization in form of improved quality, improved productivity, reduced absenteeism, reduced turnover, fewer accidents and injuries, employees retention, quality improvement and improved customer service and satisfaction.

A successful work life balance management must recognize and take into account the different elements of work life balance and develop appropriate policies (Danny, 2014). Developing a culturally well balanced work life routine allows employees to become more productive and innovative. As Capone (2010) observes, work life balancing organizations are better equipped to tackle the challenges derived from the multicultural and global marketplace. These organizations therefore gains competitive advantage over organizations that are not sensitive and diversified on issues relating to work life balance for their employees (Barney, 2011). This study looked at the effect of work life balance on staff performance in the telecommunication sector in Kenya.

\section{Study Objectives}

The study focused on the following:

a. Determining the effect of work related factors on staff performance in telecommunication sector in Kenya

b. Investigating the effect of family life and responsibilities on staff performance in telecommunication sector in Kenya 


\section{THEORETICAL BACKGROUND AND INFORMING LITERATURE REVIEW}

Peil (2003) explains that theoretical framework guide research in determining what things to measure, and what statistical relationships to look for. Theoretical framework is obviously critical in deductive, theory-testing sorts of studies (Mugenda and Mugenda, 2003). This study used moral hazard theory, information asymmetry theory and adverse selection theory to support the study.

\section{Role Theory}

Work Life Balance for any person is having the "right" combination of participation in paid work (defined by hours and working conditions) and other aspects of live. This combination will change as people move through life and have changing responsibilities and commitments in their work and personal lives (Greenhaus \& Beutell, 2010). With these definitions, it can be construed that any imbalance that is formed either creates more pressure or psychological involvement or satisfaction towards ones role as compared to other roles.

The origin of the research work life balance can be seen from the seminal work of rapport and rapport (1969). The research opines that both work and family needs time and energy. Work is an important source of income, financial stability and status. As work and family has no direct relationship with each other so conflicts is inevitable to arise (Parus, 2010).

Khan wolf, Quinn, snoek and Rosenthal, 1964) from their seminal studies associated work life balance with role theory, that is, conflicting expectations associated with different roles which the male and female has to play in their day to day life. Kanter (1977) was able to continue the research of khan (1964) proving that work and family are not independent of each other but rather have an interlink which consequently brings in conflicts between the two. With the pioneering work of Pleck (1977) there was a general consensus that work and family affect each other either positively or negatively. However, there are various extraneous variables like time, task, attitudes, stress emotions, and behaviours which also influence work life imbalance.

Conclusions from several scholars indicated that interference between work and family and the conflict arising out of it are conceptually and empirically distinct from each other (Wiley, 1987); and the field is dominated more by role theory which was derived from seminal studies of khan, Wolfe (1964). According to Cohen \& Wills (1985) however, role theory and its conflicting expectations from the two domains have detrimental effects on the well-being of male and females. This further led to the stressors - strain mode (Cohen \& Wills (1985), with work family conflicts as stressors.

\section{Spill over Theory}

Another influential theory after Pleck (1977) was the theory of spill over (Piotrkowski, 1979), based on asymmetric permeable boundaries between the work and family life domains. The spill over theory basically talked about two types of factors: job related factors and work related factors. There was a relationship established between the two domains of job related factors and work related factors like the influence of spill over theory over job context more for women than for men, whereas the converse would be true for job related factors. Further the spill over theory also invited various research scholars to identify few more factors that influence the work family dependency like compensation, benefits, and bonuses (Champoux, 1978).

Greenhaus \& Beutell (2010) further segregated a few more factors like time, task, attitudes, stress emotions, and behavioural spill over work and family. They tried to maintain either positive or negative relation between the two domains. Brutell (1988) found out that interface 
between work and family is asymmetric and work tends to influence more on family than family on work. A distinction was made between work family interface (family interfering work) and (work interfering family) greenhouse (ibid)

\section{Empirical Review}

Time spent on activities within one role generally cannot be devoted to activities within another role. Consequently, an employee whose work role interferes with their family role cannot satisfy both roles in the same time period (William, 2010). Those employees spending larger amount of time at work will have less time for family roles, consequently creating conflict. Likewise, it might be expected that the more time an employee work, the more likely he may find family issues such as care for children, older relatives, or the responsibilities interfere with work.

Time-based conflict occurs when role pressures stemming from the two different domains compete for the individual's time requiring employees to work late with little notice. This might make it difficult for employees to meet family obligations, like picking up a child at day care. The number of hours worked each week has a significant effect on reports of work-family conflict, particularly for women (Ohkubo, 2012). But the relationship between hours worked and perception of work-family conflict also reflects women's subject positions within the dominant discourse.

However, problems of coping with work and domestic responsibilities remain especially acute for employees with caring responsibilities and especially women. Some studies have found parental demands to mean less time and energy to devote to the organization and time-based work-family conflict and its consequences are believed to be most salient for women (Capone, 2012). Full-time female employees are still found to have greater concerns about childcare and housework (Schwartz \& Scott, 2000) and the greatest desire for flexible scheduling (Barney, 2011). Work-family conflict for women is also likely to be more acute given the tendency towards segregation of women into low skill and low paid jobs.

Employers have little enthusiasm for calls for greater codification of employee policies which restrict working time, putting emphasis on liberal doctrines of employee choice (to work long hours) and market freedom (Parus, 2010). But the Government also encouraged employers to offer greater flexibility to employees. In consequence, time flexible prescriptions (flexi-time and part-time working) have been offered by employers as the most common prescriptive approach to provide balance between work and life for their employees (Greenhaus \& Beutell, 2010; Raphael, 2011).

This has made prominence on the critical questions that has emerged concerning the effects of different working time arrangements on the so-called 'work-life balance' of workers (Migai, 2010). Okore (2011) recent review report and research evidence covering the effects of working time arrangements on work-life integration; reconciliation or 'balance' across paid economic activity and personal life and range of well-being and work-life balance outcomes indicates that contemporary parents working time is generally more constrained than that of yesterday due to increase of responsibilities for children and other family members.

In another study by Maruti (2008) on over 800 people working more than 48 hours a week, about a third admitted to being addicted to their work. They also reported higher levels of work dissatisfaction with other aspects of their life than those working long hours but who did not admit to addiction to work. It appears that those who work long hours may fall in to 
various types and there is need to distinguish those with high levels of work involvement from those who feel an internally-driven compulsion to work without high work involvement and those who are compelled by external circumstances to work for long hours (Rusek, 2006).

Work schedule flexibility has been found to be negatively associated with work life balance / work family conflict. The industries today are demanding work environment wherein employees are supposed to work for long hours. Higher the flexibility, lower is the work family conflict (Migai, 2010). In other words, higher the work schedule flexibility, higher is the work life balance. Working hours have consistently been linked to difficulties in balancing work and family life resulting in more number of hours and less work schedule flexibility thus leading to work family conflict (Rusek, 2006).

High workloads leading to long hours of work on a regular basis can make getting a satisfactory work-life balance more difficult. This can have a number of causes, including: insufficient staff, high turnover of staff, delays in filling vacancies, poorly designed shifts or rosters, inadequate training, poorly distributed work, poorly designed jobs and not addressing the poor performance of some team members (Rembe, 2014). This typically leads to high stress levels and burnout (Juma, 2010).

Other serious repercussions of workload also relates to depression, alcohol and drug abuse, marital and financial problems, compulsive eating disorders, and employee burnout (Maruti, 2008). According to Juma (2010), work-life balance has always been a concern of those interested in the quality of working life and its relation to broader quality of life.

While many studies have focused on work-life balance to improve organizational management of employee's wellbeing, Chandler and McEvoy (2010) explains that the pressures of work have been intensifying in recent decades. "Factors such as the advances in information technology and information load, the need for speed of response, the importance attached to quality of customer service and its implications for constant availability and the pace of change with its resultant upheavals and adjustments all demand our time and can be sources of workload and work pressure" (Khatri, 2009).

Leave typically comes up as an issue when organization examines work-life balance. The issues that emerge include when leave can be taken, difficulties in scheduling leave, whether there is sufficient cover available while people are on leave, how much notice is given that leave has been granted, leave that is withdrawn, how competing demands for leave are dealt with, how much leave is available, and is it possible for people to negotiate or buy additional leave, people not knowing or understanding arrangements related to taking leave or time-in-lieu and real or perceived unfairness about leave provisions (Cook and Heiser, 2011).

According Barney (2011), some of the things that people are looking for in their work-life balance, such as time for travel or sport, are optional. Caring responsibilities generally are not. For this reason, many organizations should pay particular attention to making it possible for people to balance work and caring responsibilities. As Fabian and Gunther (2009) explain, common issues in employees vacation in relation to work life balance that organizations should provide include managing parental leave; supporting people with partners, parents or children with significant illnesses or disabilities, caring for children before and after school and in school holidays.

Maternity leave is a leave of absence for an expectant or new mother for the birth and care of the baby (Danny, 2014). This is a very important factor in creating a work-life balance for 
families. Most companies do not offer any paid time off, for this important time in one's life. Many mothers are forced to return to work only weeks after having given birth to their children; missing out on important bonding time with their child (Khatri, 2009).

According to William (2010), at this age, newborn babies and their mother are forming an important bond and the child is learning to trust and count on their parents. Yet, they are often sent to daycare and are now being cared for by a non-family member. Chandler and McEvoy (2010) explain that men know that work alone may not provide their lives with meaning. Young men can lose their meaning of life, therefore they should be provided with a balance between paid work and personal attachments without being victimized at work.

More men are realizing that work is not their only primary source of fulfillment from life. Lado and Wilson (2014) study shows that more men are looking for alternatives to their 40-hour workweek in order to spend more time with their family. "Though working less means a smaller paycheck and higher stress levels, men are looking for flexibility just as much as women" (Barney, 2011). However, with an ever-changing society, flexibility is becoming much more apparent. "It seems that some traditional stereotypes are starting to lessen just a bit in terms of who's responsible for care of the children" (Juma, 2010). Traditionalism is becoming less frequent due to what's actually practical for each individual family.

According to Migai (2010), men often face unequal opportunity to family life as they are often expected to be the financial supporter of the family unit, The masculine ideal of a worker unencumbered by caregiving obligations is built into workplace structures and patterns of reward" (Khatri, 2009). Rembe (2014) explains that employees require leave because mental health is a balancing act that may be affected by four factors: the influence of unfavourable genes, by wounding trauma, by private pressures and most recently by the stress of working. Many people expose themselves unsolicited to the so-called job stress, because the "hard worker" enjoys a very high social recognition. These aspects can be the cause of an imbalance in the areas of life. But there are also other reasons which can lead to such an imbalance.

Migai (2010) explains that a range of strategies can address vocational issues in organization. This includes developing clear and transparent principles for approving leave; streamlining the processes for applying for leave; prompting employees to apply for leave early, reminding them to think about family, religious or cultural commitments that they may need leave for; working with employees to identify the times when work demands require that leave will be granted only in emergencies; developing protocols for negotiating or buying additional leave; developing a trained pool of casuals or relievers to provide cover while people are on leave and improving systems and documentation so that people can provide adequate cover while people are on leave.

Work-family conflict is defined as a form of role conflict characterized by the incongruence between responsibilities of the home and workplace which are mutually incompatible (Greenhaus \& Beutell, 2010). According to Dex \& Smith (2012), work-family conflict is defined as a form of inter role conflict in which the role pressures from the work and family domains are mutually incompatible in some respect. That is, participation in the work (family) role is made more difficult by virtue of participation in the family (work) role.

Parus (2010) explains that a form of work-family conflict involves role-produced strain, where strain in one role affects one's performance in another role. Potential sources of strain-based conflict include the emotional demands of the workplace (Greenhaus \& Beutell, 2010). 
Individuals facing relatively high levels of strain at work are more likely to feel conflict when family responsibilities interfere with work role, thus, it is expected that there will be a positive correlation between strain and work-family conflict.

William (2010) described three major forms of work-family conflict: time-based, strain-based, and behaviour based. This author also maintain that work-family conflict increases when the work and family roles are salient or central to the individual's self-concept and when powerful negative sanctions for compliance with role demands are inevitable. For example a male employee who has become a new father may want to focus his time and energy upon this new father role (salient family role), while his manager stresses work deadlines (salient work role) and threatens termination if the project fails (strong negative sanction). The result would be the employee suffering intensified work-family conflict. Greenhaus and Beutell (2010) suggested examining role pressures from both work and family domains, maintaining this was a fundamentally under researched area where we need a better understanding of the interactive effects of work and family role pressures.

The assumption, that involvement in one role (i.e. job) necessarily precludes attention of another (i.e. family). Such interference between role commitments leads to work-life conflict (Parus, 2010). In other words individuals perceive that they have more flexibility in terms of engaging in family commitments and responsibilities than they do for work commitments (Raphael, 2011).

There are basically two interfaces to work life conflict: Work to family interference (WIF) and family to work interference (FWI). Ohkubo (2012) states that working time of an individual are dictated by the person's employment contract or the organization commitments whereas family time is purely discretion of the individuals. The clash of time in these two aspects creates an imbalance in two directions i.e. work family interference (WFI) tends to dominate the family work interference (FWI).

As Capone (2010) observes, work home interference generally operates in two directions. First, work demands more time and energy hindering activities at the family end. For example attending an early morning meeting or marketing tours arranged by the organization leads individual to compromise on home related activities. Researchers call this as work interference with home. Second, responsibilities at home interfere with performance at work. For example worrying about sick dependents, spouse or partners responsibility many a times diverts an individual's attention towards work related responsibilities leading to family interfering work (Raphael, 2011).

\section{RESEARCH METHODOLOGY}

Research design involves planning, organizing, collection and analysis of data to provide information sought (Cooper and Schindler, 2003). The author states that each research method provides specific data. This study used descriptive research design. Descriptive design as the name suggests, attempts to describe the situation as it is and obtains complete and accurate description of a situation. It provides in-depth response that facilitates better understanding of the phenomenon under study so as to scoop the best results.

\section{Target Population}

Target population in statistics is the specific population about which information is desired. According to Ngechu (2008), a population is a well-defined set of people, services, elements, and events, group of things or households that are being investigated. The target population of this study was the 195 senior staff working at Safaricom, Airtel, Telkom Kenya's Orange and 
Essar Kenya's Yu Headquarters in Nairobi. The study focused more on the three levels of management that is top, middle and lower level management staff who are directly dealing with the day to day management of the companies.

\section{Sample and Sampling Techniques}

According to Kothari (2004) sampling is the process by which a relatively small number of individuals, objects or events are selected and analyzed in order to find out something about the entire population from which it was selected. A sample is a small portion of a targeted population using some systematic form. This research study used stratified random sampling technique because it enables the generalization of a larger population from the sample size.

The data collected from primary source was processed with an aid of the Statistical Package for Social Sciences (SPSS) software for effective quantitative analysis. Descriptive statistics such as use of frequency table was applied. The measure for the independent variable was determined by use of Likert scale, which ranks how strongly each independent variable affected the dependent variables.

\section{SUMMARY OF THE FINDINGS}

According to the findings, this study received 94\% response from the participants. This showed that the study received above average response and this contributed to the success of the study. The study incorporated views from both gender with a response of $58 \%$ for women and $42 \%$ men. All the targeted age brackets responded to the study with majority of respondents being between 26-33 years of age. This showed that data gathered reflected views from different age groups. The study also received participation from respondents with different highest levels of education with the least being certificate and highest being post graduate qualifications. This indicates that the input given to the study was rational and objective.

Based on the findings, the study established that long working hours, overtime, working over the weekend, work burden, lack of work schedule, extending office work at home, foregoing annual leave, lack of vacation, lack of flexible working time, family expectations, family responsibilities and family work conflict negatively affects staff performance in the organization. This indicates that there were several work life balance factors that affects staff performance in the telecommunication sector in Kenya.

It was also reported that management ability to help its workforce through better remuneration, good working relationship, and support of employee personal achievement were some of the better ways and strategies to improve staff performance at the workplace. Further management approaches such as staff motivation, recognition, stress management, division of labour and clear job description as well as career development were also cited as some of the better strategies to improve staff performance at the workplace.

\section{CONCLUSION}

Based on the findings, it was evident that work life balance factors such as long working hours, overtime, working over the weekend, work burden, lack of work schedule, extending office work at home, foregoing annual leave, lack of vacation, lack of flexible working time, family expectations, family responsibilities and family work conflict negatively affects staff performance at work. 


\section{RECOMMENDATIONS}

Based on the findings, this study recommends the following to improve staff performance in the companies under the telecommunication sector in Kenya; that the companies in the telecommunication sector in Kenya need to review overtime and how long its employees' works to enable them have time to rest and plan for their duties properly; introduce shifts to eliminate fatigue and boredom in relation to working over the weekend; adopt the use of delegation and clear division of labour to eliminate employees work burden; use work schedule to help employees manage their time and energy; develop work life policies ; ensure that all its employees go on annual leave when time comes; introduce vacation for its employees to refresh and rebound to break monotony and improve performance at work; develop flexible working time to enable employees plan and enjoy their duties; support employees through counseling and resources to meet family expectations and responsibilities; support employees to work better through better remuneration, cultivate good working relationship, support achievement of personal goals; and, explore management tools such as staff motivation, recognition, stress management, division of labour, clear job description and career development as part of strategies to improve staff performance at work.

\section{References}

Barney, D. M., (2011), Work life balance on employee performance: Human Resource Management Journal, volume 34, 1111-117.

Brutell, E., (1988), the impact of shiftwork on work-home interference, job attitudes and health, Ergonomics, 47, 987-1002.

Capone, S.S. (2010), Impact of employee rest on productivity: Academy of Management Journal, Vol. 12, No. 3, 454-470.

Champoux, J.E. (1978), it's about time: A study of hours worked and work spillover among law firm lawyers. Journal of Vocational Behaviour, 50, 227-248.

Chandler, E., Cacioppo, J. T. \& McEvoy, R. L. (2010), Emotional contagion [Elektronische versie]: Current directions in psychological science: a journal of the American Psychological Society, 2 (3), 96-99.

Cohen, A.B., \& Wills, E. (1985), Workaholism and relationship quality: A spillover-crossover perspective. Journal of Occupational Health Psychology, 14, 23-33.

Cook, A.B., \& Heiser, E. (2011), Crossover of stress and strain in the family and in the workplace: Research in occupational stress and well-being (Vol. 2), JAI Press/Elsevier Science.

Cooper and Schindler (2003), Social Science Research Methods, 5th Edition, London: Pearson Publishers: Sri Lanka: New Age International Publisher.

Danny, .D. (2014), Organizational commitments and staff productivity: International Journal of Management, 53(4), 299-308.

Dex, F.T., \& Smith, N.K. (2012), a meta-analysis of work-family conflict and various outcomes with a special emphasis on cross-domain versus matching-domain relations. Journal of Occupational Health Psychology, 16, 151169.

Fabian, A.B., \& Gunther, M. (2009), how job demands influence partners' experience of exhaustion: Integrating work-family conflict and crossover theory. Journal of Applied Psychology, 93, 901-911.

Greenhaus, J.H., \& Beutell, N.J. (2010), Sources of conflict between work and family roles. Academy of Management Review, 10, 76-88.

Jason, A.B., (2006), Does home life interfere with or facilitate performance? European Journal of Work and Organizational Psychology, 19, 128-149.

Juma, R.C., (2010). Changes in job and marital experience and change in psychological distress: A longitudinal study of dual-earner couples. Journal of Personality and Social Psychology, 69, 839-850. 
Keino, D. C., \& Kithae, P. P. (2016). Effects of Work Life Balance on Staff Performance in the Telecommunication Sector in Kenya. Archives of Business Research, 4(1), 129-138.

Kanter, A.B., (1977), extending the demands-control model: A daily diary study of job characteristics, work-family conflict and work-family facilitation. Journal of Occupational and Organizational Psychology, 78, 155-169.

Khatri, R. W., (2009). Emotional contagion: Gender and occupational differences. Psychology of Women Quarterly, 19, 355-371.

Kothari, .C. R. (2004), Research Methodology: Methods and Techniques, 2nd Edition, Sri Lanka: New Age International Publisher.

Lado, A.B., \& Wilson, E. (2014), The Spillover-Crossover model: In J. Grzywacs \& E. Demerouti (Eds.), Work-life balance Psychology Press.

Maruti, M. (2008), Crossover of stress and strain in the family and in the workplace: In P.L. Perrewé \& D.C. Ganster (Eds.), Research in occupational stress and well-being (Vol. 2), JAI Press/Elsevier Science.

McGinity, .N. (2014), Employee overtime: curse or a blessing? Journal of Business Management, Vol 22, No 2, pp.125.

Migai, P., (2010), Mechanisms linking work and family: Specifying the relationships between work and family constructs. Academy of Management Review, 25: 178-199.

Mugenda .O.M. \& Mugenda, A.G. (2009), Research Methods: Quantitative and Qualitative Approaches, Published by ACTS, Nairobi, Kenya.

Ohkubo, .N. (2012), Employee engagement and productivity: Tenets for Developments, OMEGA 31(2): 63-73.

Okore, S. (2011), multiple roles and role strain: Some notes on human energy, time, and commitment. American Sociological Review, 42, 921-936.

Parus, M., (2010), Work and family satisfaction and conflict: A meta-analysis of cross-domain relations. Journal of Applied Psychology, 92, 57-80.

Peil .O.M. (2003), Research Methods: Quantitative Qualitative Approaches, 2nd Edition, and Published by ACTS: Nairobi.

Piotrkowski, J.G., (1979), reconceptualizing the work-family interface: An ecological perspective on the correlates of positive and negative spillover between work and family. Journal of Occupational Health Psychology, 5, 111126.

Pleck, A.B., (1977), The Spillover-Crossover model: (Eds.), Work-life balance, Psychology Press.

Raphael, K. (2011), a meta-analytic review of work-family conflict and its antecedents. Journal of Vocational Behaviour, 67, 169-198.

Rembe, E., (2014), Spillover and crossover of exhaustion and life satisfaction among dual-earner parents: Journal of Vocational Behaviour, 67, 266-289.

Rusek, A.B., (2006), the contagion of stress across multiple roles. Journal of Marriage and the Family, 51, 175-183.

Schwartz, J. H., \& Scott, G. N. (2000), when work and family are allies: A theory of work-family enrichment.

Academy of Management Review, 31(1), 72-92.

Wiley, S.A.E., (1987), Antecedents and consequences of work-home interference among medical residents. Social Science \& Medicine, 48, 1135-1148.

William, D. S. (2010), Personality and role variables as predictors of three forms of work-family conflict: Journal of Vocational Behaviour, 55, 236-253.

Wolfe, A.B., (1964), towards a dual-process model of work-home interference. Work \& Occupations, 31, 345-366. 